\title{
On Dallas Smythe's “Audience Commodity": An Interview with Lee McGuigan and Vincent Manzerolle
}

\author{
Henry Adam Svec
}

University of New Brunswick, Fredericton, Canada, henry.adam.svec@gmail.com, http://www.henryadamsvec.ca

\begin{abstract}
This interview with Lee McGuigan and Vincent Manzerolle explores some concepts and debates charted by their new co-edited book. The Audience Commodity in a Digital Age: Revisiting a Critical Theory of Commercial Media, which both celebrates and scrutinizes Dallas Smythe's canonical 1977 essay, "Communications: Blindspot of Western Marxism". The discussion covers Smythe's contribution to the field of media studies and the state of current debates pertaining to the theory of the audience commodity, and it also touches on questions of Smythe's mainstream reception and legacy.
\end{abstract}

Keywords: Dallas Smythe, digital labour, audience commodity, critical political economy, social media.

Acknowledgement: Henry Adam Svec would like to thank Lee McGuigan and Vincent Manzerolle for their time and generosity.

\section{Introduction}

In 1977, Dallas Smythe published his seminal essay "Communications: Blindspot of Western Marxism", in which he argued that scholars of media were paying too much attention to "content" and "messages" and not enough attention to the material (economic) ground across which content and messages (TV shows and radio broadcasts) were distributed and consumed. One of his contentions was that the audience itself-and not programming, which he figured as a "free lunch", the function of which was basically to attract viewers-was the commodity form of "mass-produced, advertiser-supported communications under monopoly capitalism" (Smythe 2014, 33, 31). In other words, according to Smythe, the media industries do not only produce sitcoms or news broadcasts; from the point of view of capitalism, they make audiences to sell to advertisers.

Although the apparent novelty of the technological systems undergirding big data, digital surveillance, and social media might tempt some to focus only on novel theorists and concepts-or to cling very tightly to Marx's original distinctions-others contend that Smythe's paradigm-challenging theories are still worth consideration. Two scholars in particular, Lee McGuigan and Vincent Manzerolle (2014), have taken it upon themselves to edit a collection, The Audience Commodity in a Digital Age: Revisiting a Critical Theory of Commercial Media; the book includes Smythe's original essay, some influential critiques and responses (including essays by Graham Murdock, Eileen R. Meehan, and Sut Jhally), and recent deployments of Smythe's theory in relation to digital and social media (by Mark Andrejevic, Edward Comor, Christian Fuchs, and more). As readers will find, Smythe's essay has produced a lively, urgent, and still-unfolding discussion-one worth following from the start.

The following interview was conducted with McGuigan and Manzerolle over email, and hopefully it will serve as an accessible introduction or teaser to their new volume, which both documents and probes one of critical political economy's most high-yielding contributions.

\subsection{The Interview}

Henry Adam Svec: What was Dallas Smythe's theory of the audience commodity about? 
Lee McGuigan and Vincent Manzerolle: Dallas Smythe's theory of the audience commodity was an attempt to reckon what he considered the "economic function" of advertisersupported mass media. Based on his interpretation of critical political economy, Smythe suggested that in paying attention to commercial media people essentially "work" for advertisers-and the industrial capitalists they represent-by learning to buy certain goods and services (and to vote for certain politicians and ballot items) and by reproducing their own capacities to work as wage laborers in the economy-in-general. As part of what Smythe called the "Consciousness Industry," commercial media contribute to the maintenance of capitalist relations of production and consumption by selling audiences (and their attention) to advertisers.

\section{What was new or challenging about it when first published?}

Smythe positioned his theory against what he viewed as the prevailing approach of critical scholars studying communication and culture-that media serve primarily to manufacture support for capitalism through messages and the ideologies conveyed by those messages. For Smythe, the focus on messages, signs, and symbols-certainly the focus of mainstream communication research, which was preoccupied with manipulating variables to demonstrate simple cause-and-effect relationships-provided an inadequate basis for understanding the unique development of media systems/technologies under capitalism. Smythe sought to highlight the concrete social relations (like wage labor, exploitation, and alienation) and the commodity form of (or "within") media systems. By concentrating on ideology, critical scholars had failed to appreciate that media systems are organized primarily to produce audiences as commodities for sale to advertisers (like VICE Motherboard).

Certainly, it was provocative to claim that watching television was virtually equivalent to wage labor. Earlier critical researchers and some institutional economists had equated advertising with the management of consumer demand (e.g. Galbraith 1969; Baran and Sweezy 1966). In this view, commercial media stimulated consumption in order to keep pace with industrial outputs and to grow "The Economy". Smythe went further, arguing that this was a necessary kind of "work".

But Smythe also exaggerated the novelty of his contribution. Notwithstanding that some of his contemporaries made similar observations about the sale of audiences to advertisers (e.g. Barnouw 1978), Smythe can hardly claim to have gone beyond ideology. His discussion of the "Consciousness Industry"-a term which Smythe did not invent (see Enzensberger 1970)—echoed the ideas of other cultural critics, and remained firmly based in the critique of ideology in consumer culture.

Still, Smythe presented a compelling critique of media in consumer capitalism that still resonates today. He provoked considerable debate across media and cultural studies.

\section{Why is it important now?}

In many ways, Smythe's theory is more applicable to current media systems than it was to the broadcast era he observed. Most fundamentally, we think, Smythe was writing about the production of consumer commodities. By "consumer commodities" we mean goods people buy and use in everyday life, but also people who work and live to consume commodities. Commercial media in capitalism help produce consumers as commodities sold to advertisers and marketers. This was pretty abstract stuff in the 1970s. But his theory has proven prophetic of the contemporary interactive media environment. Today, advertiser-supported media are not only venues for disseminating messages; with two-way transmission capacity, modern media systems facilitate various forms of feedback, including user-generated content which can be considered a kind of unpaid work (such as we see on YouTube and Facebook). For example, many cable and direct broadcast satellite systems allow viewers to respond to advertisements by requesting information about products or even making an immediate purchase. Viewers in some places can order pizza directly from the TV, and for more than 15 years marketers and television executives have been working out ways to sell almost any 
item on-screen in a TV show. These strategies have been plagued by problems, and have developed inconsistently; but Smythe captured the industrial logic that underpins commercial media today. Smythe articulated his theory at a time when media gave voice to marketers; today, media are marketplaces, capable of not only promoting products, but facilitating direct purchases by viewers. And this is true not only of television, but also digital magazines and of course internet-based video content.

Theories of the audience commodity have also inspired critical research on data mining and online surveillance. It is argued that media users "work" at producing information about themselves and their behaviors, which are sold to various marketing interests. Companies of various stripes do a brisk trade in information harvested from digital media users, and media systems are organized in important ways around the production and interpretation of data-based consumer profiles. Again, a form of "work" that seemed more abstract in the context of broadcasting is increasingly concrete and observable. Regardless of disputes about whether this constitutes "labour"-and surely this work is less perilous than many other occupations-it is a matter of fact that when people use digital media (including web browsers, cable television, mobile phones, and Netflix) they produce data that are processed by additional labour into saleable commodities.

Does everyone agree on whether or not Smythe's theory should be applied today? What are some of the debates about?

There are plenty of disagreements about if and how theories of the audience commodity can be applied today. Many of these debates are arcane, parsing terminology and ferreting out "conceptual slippage". A lot of this is misguided policing of theoretical orthodoxy. Smythe was attempting to shine light on what he saw as a "blind spot" in critical theory, and he began his seminal statement on the topic with the disclaimer that he was trying "to start a debate, not to conclude one". Many of his critics apparently missed the first sentence of his essay. I am less interested in the "accuracy" of his theory-if such a thing can be said of social, cultural, and economic theory-than the fact that his ideas generated important and exciting scholarship over nearly four decades, and they continue to help people understand and think critically about media systems in capitalist societies. Smythe's arguments have value as heuristicslenses through which we can understand media and culture in capitalism.

More generally, we think Smythe's ideas have currency in popular understandings of digital media, especially in view of data mining, commercial surveillance, and user-generated content. The idea that television advertisers buy audiences is accepted as a matter of facteven beyond the specialist discourses within industry and academy. Increasingly, people are understanding this of online media. The idea that, on the Internet, if you don't pay for a product you are the product, has been popularized in memes and blogs. This sentiment is commonly attributed to Harvard professor Jonathan Zittrain, who points out that this attribution is mistaken, and it was explored deftly in Douglas Rushkoff's documentary Generation Like. Of course, Smythe argued exactly this point-though he is not recognized in most of the popular discussions about these issues.

\section{Is Dallas Smyth given due respect?}

Smythe's legacy is interestingly bifurcated. In the field of study generally referred to as "critical political economy of media/communication," Smythe is widely acknowledged as a pioneer. He is usually credited with teaching the first university course on the topic in North America. His work has been "rediscovered" in recent years as people have noticed that his ideas anticipated many developments in commercial media and technology.

Another constituency-somewhat unknown to critical theorists-acknowledges Smythe's contributions to communications policy in North America. Smythe was the first Chief Economist at the Federal Communications Commission, part of a Progressive block that held sway there in the 1940s. From the 1950s on, Smythe wrote countless articles and government 
reports about broadcast policy, television technology, telecommunications, and-somewhat tangentially-nuclear disarmament.

But, as far as we can tell, Smythe is not well known outside of the academic circles. And even within the mainstream of communications research, which is still obsessed with "proving" the linear effects of messages on behaviour (mostly in the interest of persuading people to act in one way or another), Smythe's work is rarely acknowledged. This owes, partly, to the historical exclusion of political economy from communication and media studies in general (Babe 2006). But this is changing. After a protracted standoff between political economists and cultural studies scholars in the 1990s, it seems that critical researchers across the globe have resumed the more important project of combining critiques of ideological power and economic power through attention to both messages/representations and historicallysituated institutional conditions. Smythe's work has figured prominently in some of these discussions, especially as they relate to what is called "digital labour". Perhaps more importantly, global economic crises have given renewed urgency to political projects searching for alternatives to consumer capitalism. Smythe's dedication, to building a more just way of life and to dismantling communications systems that make commodities out of human life, is as timely as ever. His rallying cry echoes in contemporary movements for change.

\title{
References
}

Babe, Robert E. 2006. The Political Economy of Knowledge: Neglecting Political Economy in the Age of Fast Capitalism (as Before). Fast Capitalism 2 (1). Accessed May 26, 2015. http://www.uta.edu/huma/agger/fastcapitalism/2_1/babe.htm.

Baran, Paul A. and Paul Sweezy. 1966. Monopoly Capitalism. London: Pelican.

Barnouw, Erik. 1978. The Sponsor. New York: Oxford University Press.

Enzensberger, Hans Magnus. 1970. Constituents of a Theory of the Media. New Left Review 64: 1336.

Galbraith, J.K. 1969. The Affluent Society, 2nd edition. Boston: Houghton Mifflin.

McGuigan, Lee and Vincent Manzerolle, eds. 2014. The Audience Commodity in a Digital Age: Revisiting a Critical Theory of Commercial Media. New York: Peter Lang.

Smythe, Dallas. 2014. Communications: Blindspot of Western Marxism. In The Audience Commodity in a Digital Age: Revisiting a Critical Theory of Commercial Media, edited by Lee McGuigan and Vincent Manzerolle, 29-54. New York: Peter Lang.

\begin{abstract}
About the Author
Henry Adam Svec

Henry Adam Svec completed a doctorate in media studies at the University of Western Ontario (2013), where his dissertation explored the meaning of technology in the American folk revival. His work has been published or is forthcoming in the Canadian Journal of Communication, Celebrity Studies, Popular Music \& Society, the Journal of Popular Music Studies, Loading..., and Fibreculture. He is currently the Media Artist in Residence at the University of New Brunswick in Fredericton, Canada, where he is working on imaginary media. For more information about his scholarship and interdisciplinary performance projects, visit www.henryadamsvec.ca.
\end{abstract}

